\title{
A TEORIA ARGUMENTATIVA DE ROBERT ALEXY E O PRINCÍPIO DA PROPORCIONALIDADE: uma análise do balanceamento de princípios e sua aplicação no Supremo Tribunal Federal.
}

\begin{abstract}
Abhner Youssif Mota Arabi*
RESUMO

O artigo pretende tratar da importância do método da ponderação, elaborado por Robert Alexy e seu uso dentro do contexto das decisões atuais dos Tribunais Constitucionais. Traz também a ponderação como um caminho para a resolução do conflito de princípios.

Palavras chave: ponderação, princípios, conflito.

ARGUMENTATION THEORY OF ROBERT ALEXY AND PROPORTIONALITY: an analysis of the ponderation method and its application in the Brazilian Supreme Court.
\end{abstract}

\begin{abstract}
This article aims to analyze the importance of the ponderation method, elaborated by Robert Alexy, in the context of the decisions made by the Constitutional Courts. It also brings the ponderation as a way of reach a solution for de collision of principles.
\end{abstract}

Key-words: ponderation, principles, collision.

\section{Introdução}

Robert Alexy é um dos mais influentes pensadores dentro da filosofia contemporânea do direito. Sua teoria é hoje uma das mais conhecidas e analisadas no estudo da argumentação jurídica, e tem servido, por diversas vezes, como base para votos em tribunais constitucionais, entre os quais figura nosso Supremo Tribunal Federal.

Alexy parte seu estudo do chamado discurso prático para então chegar ao discurso jurídico, considerando este uma espécie mais sistemática e articulada daquele. Afirmar isso significa dizer que o discurso jurídico se faz em torno de questões práticas e morais, dentro de certas condições de limitação e no qual se erige uma pretensão de correção.

Alexy afirma que o discurso prático possui seus limites e deixa espaços abertos. Para preencher tais espaços (as "lacunas de racionalidade"), propõe-se um sistema jurídico [Digite texto]

*Graduando em Direito pela Universidade de Brasília (UnB), desde o 2ำ semestre de 2009. Atualmente é estagiário na Assessoria Processual da Secretaria-Geral da Presidência do Supremo Tribunal Federal (STF). Tem experiência na área de Direito, com ênfase em Direito Processual Civil e Constitucional 
fundamentado discursivamente, e que opere com base em três principais procedimentos. Em um primeiro momento se dá a criação de normas jurídicas, que selecionem, dentro das regras do discurso prático, algumas regras ditas possíveis. Entretanto, em nenhum sistema jurídico, é-se capaz de enfrentar todos os casos concretos que surgirão apenas pela relação fato e norma. Por isso surge um segundo tipo de procedimento: a argumentação (ou discurso) jurídica. Esta argumentação também é limitada, pois é possível, e provável, que se chegue a distintos resultados por meio desta argumentação. Desse modo, não se é capaz de chegar a uma resposta correta, ficando carente, assim, o caráter do veredito necessário e esperado de uma decisão dentro de um debate judicial. Para suprir tal necessidade, formula-se um último procedimento, o processo judicial, por meio do qual se deve chegar a uma resposta final dentre as discursivamente possíveis.

O discurso jurídico também possui seus limites (um exemplo é ser possível, seguindo as mesmas regras formuladas para um discurso, chegar-se a duas posições conflitantes, mas igualmente racionais), mas o importante a se destacar é que Alexy tenta impregnar à argumentação jurídica uma pretensão de correção, que se dá por meio de uma fundamentação racional. Para que se chegue a decisões racionais e fundamentadas, sugere-se que seja seguido um método e certas regras do discurso formuladas pelo autor. É verdade que o método de Alexy pode ser contestado, mas se é possível atingir respostas conflitantes seguindo-se etapas idênticas de um método, esse mesmo método estabelece limites ao discurso jurídico, limites esses que não devem e nem podem ser ultrapassados, o que já é de grande valia.

Dentro desse método, que nasce a partir de uma pretensão de correção, fundamentação e racionalidade, destaca-se a ponderação e balanceamento ao se aplicar princípios. Tal proposta deu ensejo ao florescimento da ideia do princípio da proporcionalidade, e disto que pretendo tratar no artigo que se inicia.

\section{A pretensão de correção como parâmetro para a aplicação do direito}

A formulação de um adequado conceito de direito é, para Alexy, aquela que entrelaça duas dimensões do fenômeno jurídico: a fática/institucional (aquilo que é decretado e eficaz) e a ideal/discursiva (aquilo que é correto). Alexy dá grande ênfase à segunda dimensão ao tratar da pretensão de correção, que é pressuposto de sua teoria, como ele próprio afirma: "Minha teoria depende da tese que o direito promove, necessariamente, uma pretensão de correção"1. Correção, para Alexy (o que condiz com sua tentativa de fornecer à argumentação jurídica bases racionais), corresponde, independentemente de seu diverso conteúdo, à fundamentabilidade, ou

\footnotetext{
${ }^{1}$ ALEXY, 2007, p.20

[Digite texto]

*Graduando em Direito pela Universidade de Brasília (UnB), desde o $2^{\circ}$ semestre de 2009. Atualmente é estagiário na Assessoria Processual da Secretaria-Geral da Presidência do Supremo Tribunal Federal (STF). Tem experiência na área de Direito, com ênfase em Direito Processual Civil e Constitucional
} 
seja, a pretensão de correção se pauta por uma busca de garantias e fundamentos aos argumentos desenvolvidos. A correção é necessária visto que esta se liga à busca de justiça e à correta aplicação do direito, e para isso Alexy cita o exemplo de um artigo constitucional e de uma sentença que seriam absurdos ${ }^{2}$. Além disso, pressupõe-se que aqueles que participam de um discurso, o fazem tendo em vista firmar afirmações que se pautem por um conteúdo verdadeiro, o que expressaria a pretensão de correção.

A teoria do discurso desenvolvida por Alexy se pauta em um procedimento de correção prática, e o procedimento de um discurso é sua argumentação. O argumentar racional segue um procedimento estabelecido por regras que devem expressar, no âmbito do discurso, condições de liberdade e igualdade. Essa seria a constituição do discurso ideal. O discurso ideal é distinto do discurso real (por isso mesmo que ele é chamado de ideal), mas serve aquele como uma idéia regulativa deste, dentro de uma pretensão de correção. "O discurso ideal, como idéia regulativa, e a pretensão de correção são, desse modo, dois lados de uma matéria"3.

No âmbito do atual Estado Constitucional Democrático de Direito, a teoria do discurso e seu conteúdo devem atender e se relacionar com duas exigências tidas como essenciais: os direitos fundamentais e a democracia. Na relação entre discurso e democracia, diz Alexy

O princípio do discurso exige democracia deliberativa. A democracia deliberativa é mais do que um procedimento para a produção de uma compensação de interesses ótima abaixo do limite de ditadura ou guerra civil. Nela, o plano dos interesses e do poder é coberto por um plano dos argumentos, no qual todos os participantes lutam por uma solução política correta. $^{4}$

O plano de democracia favorece ainda mais o florescimento dos princípios. No processo discursivo estes estão presentes, por exemplo, nas regras do discurso; liberdade e igualdade

\footnotetext{
${ }^{2}$ No exemplo do artigo absurdo, o autor formula uma situação de um estado X, no qual a minoria oprime a maioria e pretende preservar tal realidade. Nesse sentido, institui-se uma nova Constituição, cujo artigo primeiro dispõe que "X é uma república soberana, federal e injusta". Tal cláusula da injustiça é nitidamente viciosa, e decorre de um absurdo, de uma contradição entre a pretensão de correção de uma Constituição e a afirmação da injustiça. Já no segundo exemplo, trata-se de uma sentença prolatada nos seguintes termos: "O acusado é, o que é uma interpretação falsa do direito vigente, condenado a uma pena privativa de liberdade para toda a vida". Novamente há uma contradição, de onde deriva a absurdidade do enunciado: Com um sentença judicial, espera-se existir a pretensão de correção, da correta aplicação do direito; e não que seja uma afirmação falsa (ibidem, p. 22).

${ }^{3}$ ibidem, p. 29.

${ }^{4}$ ALEXY, 2003, p. 35.
}

[Digite texto]

*Graduando em Direito pela Universidade de Brasília (UnB), desde o $2^{\circ}$ semestre de 2009. Atualmente é estagiário na Assessoria Processual da Secretaria-Geral da Presidência do Supremo Tribunal Federal (STF). Tem experiência na área de Direito, com ênfase em Direito Processual Civil e Constitucional 
devem ser constituintes do discurso. Desses dois princípios maiores, decorrem outros, conforme se nota na citação seguinte: “Todos os outros direitos fundamentais são ou casos especiais de ambos esses direitos ou meios necessários para a produção e asseguramento de uma medida suficiente de liberdade e igualdade [...]" (ALEXY, 2003, p. 34)

A existência dos princípios é importante, pois estes preenchem a insuficiência das leis. Estas são incapazes de prever todas as possíveis hipóteses de incidência, situação na qual bastaria uma subsunção do fato à norma para que solucionado fosse um conflito. Nesse sentido se coloca a pretensão de correção: esta deve se deixar fazer por uso de princípios e da tese do caso especial.

A tese do caso especial é a de que o discurso jurídico é uma espécie do discurso prático, tendo a peculiaridade de a correção na argumentação jurídica se prender aos limites do próprio sistema jurídico, ou seja, daquilo que foi estabelecido por medida de autoridade ou institucionalmente. Já a argumentação por princípios é mais complexa e exige cuidados. Inicialmente, importante se faz a distinção feita por Alexy entre princípios e regras. As regras seriam deveres definitivos, ou seja, cumpridos seus pressupostos fáticos deve se dar suas conseqüências. As regras, por meio da subsunção, ou se aplicam ou não se aplicam. Já os princípios seriam mandamentos de otimização nos quais está contido um "dever ideal", e não um dever definitivo. Para a aplicação dos princípios Alexy defende a ponderação (ou balanceamento), na qual tomam parte inclusive princípios de ordem axiológica, promovendo-se assim uma reaproximação entre direito e moral. "Questões sobre distribuição correta e compensação correta são questões de justiça. Questões de justiça, porém, são questões morais. Assim, a pretensão de correção funda, também, no plano de aplicação do direito, uma união necessária de direito e moral” (ALEXY, 2003, p. 40). É por esse caminho da ponderação como método de aplicação dos princípios, e, portanto, do direito, que se guiará o presente artigo.

O ponto de partida do argumento de princípios é que a pretensão de correção, então, quando uma ponderação é possível, pede uma ponderação. Os objetos de ponderação unicamente possíveis, porém, são princípios. Como a pretensão de correção necessariamente faz parte do direito, também a ponderação, exigida por ela, faz parte necessariamente do direito. Mas se as ponderações fazem parte necessariamente do direito, então também os objetos de ponderação. A pretensão de correção leva, portanto, a isto, que os princípios, que formam os fundamentos para as regras antigas, como também para as novas a serem criadas, devem ser incluídos no conceito de direito. Desse modo, os fundamentos ideais convertem-se para aquilo que é definitivamente devido em componente do direito. ${ }^{5}$

\footnotetext{
${ }^{5}$ ALEXY, 2003, p. 38.

[Digite texto]

*Graduando em Direito pela Universidade de Brasília (UnB), desde o 2o semestre de 2009. Atualmente é estagiário na Assessoria Processual da Secretaria-Geral da Presidência do Supremo Tribunal Federal (STF). Tem experiência na área de Direito, com ênfase em Direito Processual Civil e Constitucional
} 


\title{
3 A ponderação como solução para o conflito de princípios e direitos fundamentais.
}

No momento da aplicação do direito, várias são as complexidades. Uma delas reside na interpretação dos princípios e direitos fundamentais, contidos, implícita ou explicitamente, na maioria das atuais Constituições. As colisões são tidas por Alexy como inevitáveis dentro de qualquer "catálogo de direitos fundamentais", e podem ser amplas (quando colidem com normas e/ou princípios) ou restritas (quando colidem com outros direitos fundamentais); podendo estas últimas ser entre direitos fundamentais idênticos ou distintos. Tais colisões são complexas, e propõe-se a elas uma solução: a ponderação.

O olhar sobre o fenômeno da colisão de direitos fundamentais trouxe à luz conjunturas extremamente diferentes que, porém, têm algo em comum: todas as colisões podem ser somente então solucionadas se ou de um lado ou de ambos, de alguma maneira, limitações são efetuadas ou sacrifícios são feitos. ${ }^{6}$

O primeiro ponto que Alexy assinala é que os direitos fundamentais possuem sim força vinculativa, ou, de outro modo, a colisão aludida desapareceria enquanto um problema jurídico, e seria de outra ordem (moral, política...). "Direitos fundamentais são essencialmente direitos do homem transformados em direito positivo" (ALEXY, 2003, p, 63). Uma segunda questão abordada pelo autor é se os direitos fundamentais possuem o caráter de regras ou de princípios, e chega-se à conclusão de que colisões de direitos fundamentais devem ser consideradas como colisão de princípios.

\begin{abstract}
As colisões de direitos fundamentais [...] devem ser designadas como colisões de princípios. O procedimento para a solução de colisões de princípios é a ponderação. Princípios e ponderações são dois lados do mesmo objeto. Um é do tipo teórico-normativo, outro, metodológico. [...] O litígio sobre a teoria dos princípios é, com isso, essencialmente, um litígio sobre a ponderação. ${ }^{7}$
\end{abstract}

A ponderação é parte integrante do chamado princípio da proporcionalidade. Este princípio é constituído por três fases: (i) adequação (ou idoneidade), (ii) necessidade, (iii) proporcionalidade em sentido estrito (ponderação). A adequação consiste na análise dos meios empregados para se chegar ao resultado ao qual se aspira; se são, estes meios, idôneos ou não;

\footnotetext{
${ }^{6}$ ALEXY, 2003, p. 62.

${ }^{7}$ ALEXY, 2003, p. 64.
}

[Digite texto]

*Graduando em Direito pela Universidade de Brasília (UnB), desde o $2^{\circ}$ semestre de 2009. Atualmente é estagiário na Assessoria Processual da Secretaria-Geral da Presidência do Supremo Tribunal Federal (STF). Tem experiência na área de Direito, com ênfase em Direito Processual Civil e Constitucional 
isto é, deve-se tentar melhorar uma dada posição sem que nasçam desvantagens para outras. A questão da necessidade se ocupa da análise da existência ou não de um outro modo de decisão que seria menos interveniente em um dos direitos fundamentais ou princípios em questão; ou seja, deve-se escolher, dentre dois meios que igualmente favorecem um princípio $\mathrm{P} 1$, aquele que menos prejudica P2. A proporcionalidade em sentido estrito opera por meio da Lei de Ponderação, enunciada nos seguintes termos: "Quanto mais alto é o grau do não-cumprimento ou prejuízo se um princípio, tanto maior deve ser a importância do cumprimento do outro". $\mathrm{O}$ objetivo da formulação de tal método, aliado às regras do discurso, é conferir à argumentação jurídica e ao processo decisório o caráter de fundamentação e racionalidade. Percebe-se que os dois primeiros passos se referem a questões fáticas, sendo somente o terceiro eminentemente jurídico.

O princípio da proporcionalidade, em seu sentido amplo, foi mais completamente desenvolvido pela primeira vez pelo Tribunal Constitucional Alemão em 1958, na chamada sentença-Luth ${ }^{8}$. O que se começou a aplicar foi que quando, no caso a ser analisado, encontra-se de algum modo, e em algum dos lados limitação a um direito fundamental, deve-se proceder, como método para a resolução da limitação, um balanceamento entre os princípios constitucionais colidentes. A grande questão é até onde se pode restringir um princípio sem, no entanto, eliminá-lo de dentro de um determinado sistema jurídico. Por isso usa-se a ponderação/balanceamento; para os casos nos quais custos e sacrifícios são inexoráveis. Podese, ainda, designar três etapas para o exercício da ponderação.

Em um primeiro passo deve ser comprovado o grau do não-cumprimento ou prejuízo de um princípio. A isso deve seguir, em um segundo passo, a comprovação da importância do cumprimento em sentido contrário. Em um terceiro passo deve, finalmente, ser comprovado, se a importância do

\footnotetext{
${ }^{8} \mathrm{O}$ caso consiste em uma ação intentada por Veit Harlan contra Eric Luth. Harlan era um alemão, produtor de cinema e durante as décadas de 40/50 esteve à frente de filmes que propagavam a idéia nazista, e que representavam, no cinema, os judeus de uma forma negativa e odiosa. Por isso, Luth, um judeu que à época presidia o Clube de Imprensa de Hamburgo, comandou um boicote ao filme Jud Süß que se tornou um fracasso de público e um grande prejuízo. Harlan, então, acreditando que Luth havia violado o Direito Civil alemão intentou contra este uma ação (sustentando que todo aquele que causa prejuízo deve cessar o ato danoso e reparar os danos causados). Luth, que alegava sempre o apregoado direito de liberdade, saiu perdedor em todas as instâncias ordinárias e o caso acabou por chegar ao Tribunal Federal Constitucional alemão em 1958.

[Digite texto]

*Graduando em Direito pela Universidade de Brasília (UnB), desde o 2ำ semestre de 2009. Atualmente é estagiário na Assessoria Processual da Secretaria-Geral da Presidência do Supremo Tribunal Federal (STF). Tem experiência na área de Direito, com ênfase em Direito Processual Civil e Constitucional
} 
cumprimento do princípio em sentido contrário justifica o prejuízo ou nãocumprimento do outro. ${ }^{9}$

A ponderação se justifica para balancear, ou melhor, corrigir desproporcionalidades entre intervenções reais e hipotéticas, isto é, dada uma violação a um direito fundamental (intervenção fática), deve-se ocorrer uma intervenção hipotética de mesmo peso e gravidade (como uma indenização, por exemplo). Alexy não considera, é claro, que a ponderação abre lugar à arbitrariedade, mas sim a um argumentar racional que justifique a tomada de decisões. Esse seria um método que aumentaria a importância e força dos princípios e direitos fundamentais dentro de um ordenamento jurídico; dentro do discurso e argumentação jurídicos.

\section{$4 \quad$ A Teoria de Alexy e o Supremo Tribunal Federal}

Alexy, assim como sua teoria, tem sido bastante usado em pesquisas e decisões atuais. No Supremo Tribunal Federal brasileiro, verifica-se uma crescente influência do autor, principalmente a partir do ano de 2002, ano de ingresso do Ministro Gilmar Mendes na corte suprema. Como se sabe, o referido ministro possui uma formação acadêmica de grande influência germânica, e muito se utiliza de Alexy na proclamação de seus votos e no modo como pensa que deva ser aplicado o Direito.

Em março de 2003, foi a julgamento no tribunal pleno do STF a Intervenção Federal (IF) de número 171-4/SP, referente ao pagamento de precatórios judiciais, caso no qual o pedido de intervenção foi indeferido. Percebe-se já na ementa do referido julgado, que esse é um caso no qual a teoria de Alexy encontrou aplicação prática. Vê-se no item 5 da ementa: "A intervenção, como medida extrema, deve atender à máxima da proporcionalidade". O redator designado para o Acórdão foi o Min. Gilmar Mendes, e no voto deste encontra-se ainda mais a influência da ponderação e da proporcionalidade, além de várias alusões a Alexy. Logo no início diz o ministro: "Diante deste conflito de princípios constitucionais, considero adequada a análise da legitimidade da intervenção a partir de sua conformidade ao princípio constitucional da proporcionalidade". Formando sua definição do que seja a proporcionalidade, chega-se â idéia de "limite dos limites", isto é, "o princípio ou máxima da proporcionalidade determina o limite último da possibilidade de restrição legítima de determinado direito fundamental”. Em seu voto, a ponderação é expressamente adotada como meio solução de conflitos entre

\footnotetext{
${ }^{9}$ ALEXY, 2003, p. 111.

[Digite texto]

*Graduando em Direito pela Universidade de Brasília (UnB), desde o $2^{\circ}$ semestre de 2009. Atualmente é estagiário na Assessoria Processual da Secretaria-Geral da Presidência do Supremo Tribunal Federal (STF). Tem experiência na área de Direito, com ênfase em Direito Processual Civil e Constitucional
} 
princípios, e as três etapas da ponderação são fielmente cumpridas ("Diante de tais circunstâncias, cumpre indagar se a medida extrema da intervenção atende, no caso, às três máximas parciais da proporcionalidade").

Inicialmente já se verifica, no voto, a ausência da adequação da intervenção solicitada ("É duvidosa, de imediato, a adequação da medida da intervenção"). Segundo o ministro, a substituição da Administração Pública do Estado por um Interventor federal não resolveria a situação, visto que este estaria sujeito às mesmas limitações assinaladas, e as dificuldades financeiras seriam as mesmas. Assim, conclui-se que "Enfim, resta evidente que a intervenção, no caso, sequer consegue ultrapassar o exame da adequação, o que bastaria para demonstrar sua ausência de proporcionalidade".

Mesmo assim, prossegue-se nos passos na ponderação chegando-se à fase da análise da necessidade, e esta também não é visualizada pelo ministro no caso. ("Também é duvidoso que o regime de intervenção seja necessário, sob o pressuposto de ausência de outro meio menos gravoso e igualmente eficaz.”). Ou seja, nomear um interventor e substituir a Administração por ele teria um peso mais drástico do que tentar resolver o caso de outro modo. Em suma, existe uma alternativa distinta da proposta à corte que seria menos danosa e igualmente eficaz e, assim, o meio proposto não é necessário.

Por fim, é também considerado a terceira fase de proporcionalidade estrita. Reproduzo, aqui, a parte do voto referente a tal ponto: "A intervenção não atende, por fim, ao requisito da proporcionalidade em sentido estrito. Nesse plano, é necessário aferir a existência de proporção entre o objetivo perseguido, qual seja o adimplemento de obrigações de natureza alimentícia, e o ônus imposto ao atingido que, no caso, não é apenas o Estado, mas a própria sociedade. Não se contesta, por certo, a especial relevância conferida pelo constituinte aos créditos de natureza alimentícia, Todavia, é inegável que há inúmeros outros bens jurídicos de base constitucional que estariam sacrificados na hipótese de uma intervenção pautada por um objetivo de aplicação literal e irrestrita das normas que determinam o pagamento imediato daqueles créditos". Percebe-se, no trecho citado, justamente o que foi aludido na parte teórica do artigo. Em uma situação de conflito, na qual o sacrifício a pelo menos um princípio é inevitável, opta-se por fazer uma ponderação que leve a uma conclusão racional.

No caso, pode-se identificar os princípio colidentes como sendo, de um lado, o princípio de que os créditos de natureza alimentícia sejam pagos (favorecendo a intervenção), e de outro lado o princípio e prerrogativa constitucional da autonomia dos entes federativos. Diz-se que houve, de acordo com o voto analisado, uma "relação de precedência condicionada", isto é, nas

\section{[Digite texto]}

*Graduando em Direito pela Universidade de Brasília (UnB), desde o $2^{\circ}$ semestre de 2009. Atualmente é estagiário na Assessoria Processual da Secretaria-Geral da Presidência do Supremo Tribunal Federal (STF). Tem experiência na área de Direito, com ênfase em Direito Processual Civil e Constitucional 
peculiaridades do caso, mostrou-se o porque e as condições da prevalência de um princípio sobre outro.

Por fim, como já era de se esperar pelo que se notou ao longo do voto proferido, o Ministro Gilmar Mendes terminou por indeferir o pedido, posição seguida pela maioria da corte e a que se sagrou lavrada no já aludido acórdão.

\section{Conclusão}

Por certo, a teoria de Alexy tem sido alvo de críticas. Klaus Günther, por exemplo, anota que o autor em estudo não diferencia de forma clara dois tipos possíveis de discursos em relação às normas: o discurso de justificação de uma norma e o de aplicação desta. Alexy, ao construir sua lógica da argumentação jurídica sob o discurso de fundamentação, o faz como uma espécie particular do discurso prático; o que segundo Gunther, só seria possível por meio de uma universalização da ética discursiva, o que não é possível no discurso jurídico. Não se falaria, assim, numa pretensão de correção, mas pretensão de uma aplicação apropriada das normas válidas. Habermas vai em sentido semelhante ao dizer que ao trabalhar a ponderação de princípios com base em uma "ordem concreta de valores", acaba-se por confundir normas e valores; identidade que só seria possível por meio de uma universalização objetiva de valores: a ponderação passaria a sim a se mostrar como uma aplicação de valores ao caso concreto; não se identificando as normas constitucionais efetivamente conflitantes e fazendo com o que o uso de princípios como o da proporcionalidade, por exemplo, não seja mais do que instrumento retórico.

Não obstante tais críticas, a teoria de Robert Alexy ainda é muito viva nas discussões jurídico-filosóficas atuais, seja no âmbito acadêmico, filosófico, jurisprudencial ou nos tribunais. Sua teoria da argumentação é uma sequiência do desenvolvimento de tal campo temático reinaugurado na década de 50 do século XX por Theodor Viehweg e Chaim Perelman, a partir de uma retomada dos saberes da tópica e retórica antigas, e dos estudos de Aristóteles. Tal retomada e foi continuada por Stephen Toulmin e Neil MacCormick e também por Alexy.

Tentar fundamentar o discurso jurídico, isto é, argumentar juridicamente de forma racional, é um caminho difícil. O que oferece Alexy é um método para que se atinja o citado objetivo. Alguns dirão que tal meta é inatingível, mas o fato é que tal caminho tem sido usado. estagiário na Assessoria Processual da Secretaria-Geral da Presidência do Supremo Tribunal Federal (STF). Tem experiência na área de Direito, com ênfase em Direito Processual Civil e Constitucional 
O que se tentou mostrar nesse artigo é como, a partir de um prévio e breve desenvolvimento teórico, encontra-se a aplicação do método alexyano no momento da aplicação do direito. Muitos são os nomes dados a tal método: o conhecido princípio da proporcionalidade, que visa o limite dos limites, por meio de uma ponderação, que deve ser realizada nos momentos de colisão de princípios, por meio de uma relação de precedência condicionada. O fim é o mesmo: tornar real a pretensão de correção que Alexy considera inerente ao próprio conceito de Direito. Atingir a correção, isto é, aplicar corretamente o Direito, inclusive de maneira justa, de forma a conciliar o real com o ideal, o deontológico com o fático é o que devem desejar nossos juristas e, nesse sentido, a teoria de Alexy deve ser enaltecida.

\section{Referências Bibliográficas}

ALEXY, Robert. Teoria da Argumentação Jurídica, tradução de Zilda Hutchinson Schild Silva. São Paulo: Landy Editora, 2001.

A institucionalização da razão, In ALEXY, Robert Constitucionalismo Discursivo, tradução de Luís Afonso Heck. Porto Alegre: Livraria do Advogado editora, 2007; pp. 19-40.

Direitos Fundamentais, ponderação e racionalidade, In ALEXY, Robert Constitucionalismo Discursivo, tradução de Luís Afonso Heck. Porto Alegre: Livraria do Advogado editora, 200; pp. 105-116.

Colisão de direitos fundamentais e realização de direitos fundamentais no estado de direito democrático, In Revista de Direito Administrativo, n. 217, jul/set 1999; pp. $67-80$.

Direitos Fundamentais no Estado Constitucional Democrático, In Revista de Direito Administrativo, n. 217, jul/set 1999; pp. 55-66.

Justicia como corrección, tradução de Ana Inés Haquin. In Doxa, Cuadernos de filosofia Del derecho, n. 26, Departamento de Filosofía del Derecho/Universidad de Alicante; pp. 5-26.

[Digite texto]

*Graduando em Direito pela Universidade de Brasília (UnB), desde o $2^{\circ}$ semestre de 2009. Atualmente é estagiário na Assessoria Processual da Secretaria-Geral da Presidência do Supremo Tribunal Federal (STF). Tem experiência na área de Direito, com ênfase em Direito Processual Civil e Constitucional 
RFD- Revista da Faculdade de Direito- UERJ, v. 2, n. 21, jan./jun. 2012

ATIENZA, Manuel. As Razões do Direito: teorias da argumentação jurídica tradução de Maria Cristina Gumarães Cupertino. São Paulo, Landy Editora, 2006.

MARMELSTEIN, George. 50 Anos do Caso Lüth: o caso mais importante da história do constitucionalismo alemão pós-guerra. Disponível em $<$ http://direitosfundamentais.net/2008/05/13/50-anos-do-caso-luth-o-caso-maisimportante-da-historia-do-constitucionalismo-alemao-pos-guerra>

SUPREMO TRIBUNAL FEDERAL, IF 171-4/SP. Rel. Min. Marco Aurélio, julgamento em 26/03/2003, publicado no DJ em 01/08/2003; disponível em http://redir.stf.jus.br/paginador/paginador.jsp?docTP=AC\&docID=80923. estagiário na Assessoria Processual da Secretaria-Geral da Presidência do Supremo Tribunal Federal (STF). Tem experiência na área de Direito, com ênfase em Direito Processual Civil e Constitucional 